
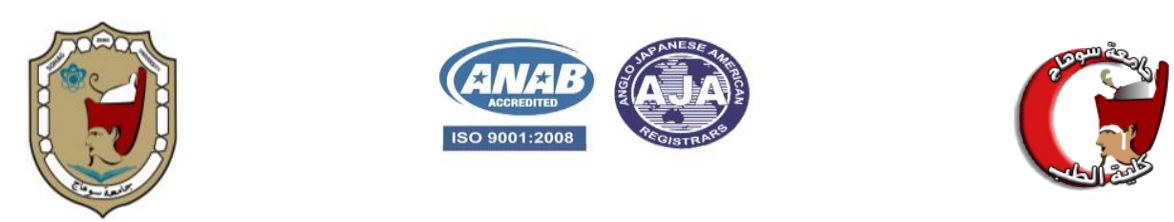

\title{
Expression of Vascular Cell Adhesion Molecule-1 (VCAM-1) in Invasive Ductal Carcinoma of the Breast
}

\section{Sheren FM Ahmed*, Nagwa Abd El-Sadek Ahmed*, Kamal A A Hassanein**, and Eman Muhammad Salah El-Deen Muhammad*.}

*The Department of Pathology, Faculty of Medicine, Sohag University, Egypt.

** The Department of General Surgery, Faculty of Medicine, Sohag University, Egypt.

\begin{abstract}
Background and Aim: VCAM-1 (CD106) expressed mainly on activated endothelial cells in response to pro-inflammatory cytokines. Recent evidences suggest that it is closely correlated with tumor formation, angiogenesis and cancer progression. The aim of the current study was to evaluate expression status of VCAM-1 in mammary invasive ductal carcinoma (IDC), and to correlate its expression with some known clinicopathological data.

Methods: Formalin-fixed paraffin embedded tissue blocks of 58 specimens of IDC were evaluated for VCAM-1 expression by immunohistochemistry (IHC). Correlation of VCAM-1 expression with different clinicopathological data was measured statistically.
\end{abstract}

Results: Up-regulation of VCAM-1 expression was frequently observed in less differentiated tumors and within advanced stages with poor Nottingham prognostic index (NPI). VCAM-1 overexpression was significantly associated with the presence of lymph node metastasis (LNM), lymphovascular invasion (LVI), and prominent lymphocytic infiltration. There was no significant association of VCAM-1 expression with patients' age, tumor laterality, tumor size, muscle or skin invasion, and presence of in situ component.

Conclusion: VCAM-1 molecule could promote LVI and LNM. VCAM-1 is a potential independent prognostic factor for breast carcinoma.

Abbreviations: CD: Cluster of differentiation, IDC: Invasive ductal carcinoma, IDCNST: Invasive ductal carcinoma of no specific type, IHC: Immunohistochemistry, LNM: lymph node metastasis, LVI: lymphovascular invasion, NPI: Nottingham prognostic index, VCAM-1: Vascular cell adhesion molecule.

Keywords: VCAM-1, Breast carcinoma, IDC, CAMs, Tumor progression

\section{Introduction:}

VCAM-1 is a $110 \mathrm{kDa}$ trans-membrane sialoglycoprotein and a member of immuneglobulin superfamily. It is expressed on many different types of endothelial and stromal cells mediating cellular adhesion. Recent findings suggest that VCAM-1 is closely correlated with tumor formation and cancer progression. It is also proved as an imp- ortant factor to predict the prognosis and to determine the patients at high risk for metastasis [1].

VCAM-1 is aberrantly expressed in various cancer cells promoting invasion and metastasis to distant organs. It also promotes angiogenesis, metastasis and survival of breast cancer cells into lung, bone, and brain. It has emerged as a 
diagnostic and prognostic marker in breast carcinoma and as a novel target in anti-cancer therapy [2]. Previous studies evaluating VCAM-1 expression focused mainly on its circulating level. Few studies were conducted to evaluate VCAM-1 expression in solid tumor tissues that is suspected to be more reliable indicator in elucidating the relationnship between VCAM-1 expre-ssion levels and prognosis [3].

\section{Materials and Methods}

\section{Tissue samples:}

Approval to perform this work was obtained from the Institutional Research Ethical Committee. Formalinfixed paraffin-embedded tissue blocks of 58 specimens of IDC were retrieved in the period from January 2018 to June 2019, from Pathology Department, Sohag University Hospitals, Egypt. Specimens that fulfilled complete clinical data were included. Cases with history of pre-operative anti-cancer therapy or with insufficient clinical data were excluded. Clinical and pathological da-ta were obtained from the patients`clinical files and pathology reports. Histopathological grading was done according to the Nottingham Histolo-gical Score System (NPI); modification of Scarff-BloomRichardson grading system. Tumors were staged according to eighth edition of AJCC TNM staging system [4,5].

\section{Immunohistochemistry:}

$4 \mu \mathrm{m}$ thick sections were deparaffinized in xylene and hydrated by graded alcohols. Endogenous peroxidase activity was blocked by incubation in $0.3 \%$ $\mathrm{H} 2 \mathrm{O} 2$ for 20 minutes at room temperature, followed by washing in two changes of phosphate buffer solution (PBS). Heating tissue section at $70^{\circ} \mathrm{C}$ for 20 minutes in Ethylenediaminetetraacetic acid (EDTA) was done for antigen retrieval. Following washing twice in PBS, the sections were incubited with mouse monoclonal antiVCAM-1 antibody (Catalog \# 0335, Activated Endothelial Marker, Clone 1.4C3, ScyTek Corporation, Fremont, USA) at dilution 1/50 for overnight at $4^{\circ} \mathrm{C}$. After washing in PBS, the sections were incubated with a biotinylated secondary antibody for 30 minutes at room temperature. Finally sections were incubated with streptavidin peroxidase for 10 minutes, also preceded and followed by washing twice in PBS for five minutes each. DAB chromogen was freshly prepared by adding DAB chromogen to DAB substrate at a concentration of 1:25. Fifty microliter from the freshly prepared solution was applied to each tissue section and incubated at room temperature until the positive control showed staining then the sections were washed in distilled water. The sections were counterstained by hematoxylin stain for half a minute then rapidly washed in tap water to remove extra dye. The sections were dehydrated, cleared and mounted as usual. Positive and Negative Controls, placenta sections worked as positive control for the IHC process (Fig. 1A). Negative control sections were prepared from breast carcinoma sections by adding PBS instead of primary antibody.

\section{Scoring of immunoreactions:}

VCAM-1 positivity was identified as membranous or cytoplasmic brown staining of neoplastic cells with ignoring the stromal staining. The expression level of VCAM-1 was measured by calculating a total immunoreactive score (IRS) which is defined as the product of multiplying of a proportion score and intensity score. The proportion score is the estimated proportion of positively stained tumor cells $(0$ : < 10\%, 1: $11 \%-20 \%, 2: 21 \%-75 \%$, and 3 : $>75 \%)$. The intensity score represents the estimated staining intensity ( 0 : no 
staining, 1: weak, 2: moderate, and 3: strong). The total score ranges from 0 to 9 with VCAM-1 -ve/low or overexpression defined as a total score $<3$ and $\geq 3$, respectively [6].

\section{Statistical analyses:}

The statistical software SPSS (Version 20) was used for data analysis. Quantitative data was represented as mean, standard deviation (SD), median and range. The Chi-square test was used to compare categorical features. $p$ value was considered significant if it was less than 0.05 .

\section{Results}

The current study included 58 cases of IDC treated surgically by modified radical mastectomy. The patients' ages ranged from 22-70 years with mean \pm SD and median was $49.83 \pm 9.34$ and 50 years, respectively. The size ranged from $1-10 \mathrm{~cm}$ with mean $\pm \mathrm{SD}$ and median were $5.39 \pm 2.36 \mathrm{~cm}$ and $5 \mathrm{~cm}$, respectively.

Histologically, the tumors were classified as IDC-NST in $44(76 \%)$ and rare special subtypes in 14 (24\%). Among the investigated cases, $7(12 \%)$ of tumors were grade I, $29(50 \%)$ were grade II, and $22(38 \%)$ tumors were grade III. Histologically normal mammary tissue and in situ component was found adjacent to the invasive tumor tissue in $20 / 58(34 \%)$ and $27 / 58(47 \%)$ cases, respectively. The clinical and pathological findings of the cases included in the present study were summarized in (Table 1).

Predominantly cytoplasmic expression of VCAM-1 was observed with some cases showed associated membranous expression (Fig 1). VCAM-1 was overexpressed in $32 / 58(55 \%)$ of cases of IDC from them $26 / 32(81 \%)$ cases were IDC-NST. VCAM-1 expression was dichotomized into 2 groups, overexpressing cases (total score >3) and ve/low expressing cases (total score, 0 3 ). Using these appropriate cutoff points, VCAM-1 was overexpressed in $32 / 58(55 \%)$ of specimens, and showed -ve/low expression in 26/58 (45\%) of specimens. Different clinical and pathological variables of IDC cases were summarized in (Table 1).

Among the studied parameters; VCAM-1 showed statistically significant positive correlation with tumor grade $(\mathrm{p}=0.008)$, stage $(\mathrm{p}=0.002), \mathrm{NPI}$ $(\mathrm{p}<0.001), \quad$ LNM $\quad(p=0.012)$, tumor lymphocytic infiltration $(\mathrm{p}=0.021)$ and LVI $(\mathrm{p}=0.007)$ as illustrated in (Graph 1A\&1B). There was no significant association between VCAM-1 expression and patients' age, tumor laterality, size of tumor, and histologic subtype. Also, no significant correlation was found between its expression and invasion of muscle, skin or surgical resection margins. 

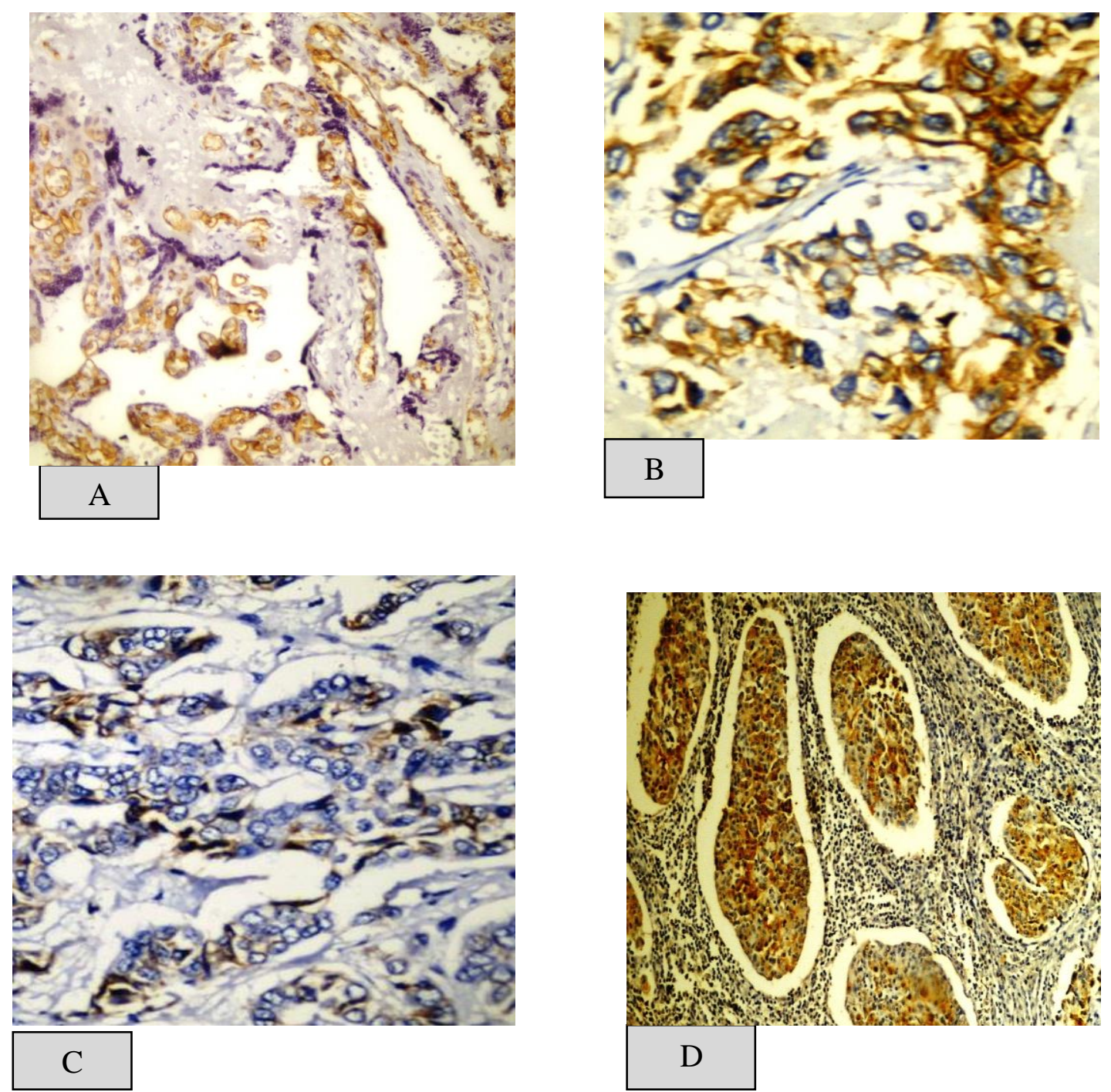

Figure 1: Representative IHC Staining of VCAM-1 (A) Placenta as positive control with VCAM-1 overexpression, (B) IDC-NST (grade III) showing cytoplasmic VCAM-1 overexpression, (C) IDC-NST (grade II) with -ve/low expression of VCAM-1, (D) Medullary carcinoma with cytoplasmic VCAM-1 overexpression. Original magnification is $200 \mathrm{X}$ in $\mathrm{D}$ and $400 \mathrm{X}$ in others. 
SOHAG MEDICAL JOURNAL

Vol. 24No. 3July
Expression of Vascular Cell Adhesion Molecule-1 (VCAM-1 Nagwa Abd El-Sadek Ahmed

\begin{tabular}{|c|c|c|c|c|}
\hline \multirow{2}{*}{$\begin{array}{c}\text { Clinicopathological } \\
\text { Parameter }\end{array}$} & \multirow{2}{*}{$\begin{array}{l}\text { No. of cases } \\
\quad(58)\end{array}$} & \multicolumn{2}{|c|}{ VCAM-1 Expression } & \multirow[b]{2}{*}{$p$ value } \\
\hline & & $\begin{array}{c}\text {-ve/low expression } \\
\mathrm{N}=26(45 \%) \\
\end{array}$ & $\begin{array}{c}\text { Over expression } \\
\mathbf{N}=\mathbf{3 2}(\mathbf{5 5 \%})\end{array}$ & \\
\hline $\begin{array}{l}\text { Age } \\
\quad \leq 50 \text { years } \\
>50 \text { years }\end{array}$ & $\begin{array}{l}28 \\
30\end{array}$ & $\begin{array}{l}13(46 \%) \\
13(43 \%)\end{array}$ & $\begin{array}{l}15(54 \%) \\
17(57 \%)\end{array}$ & $\begin{array}{c}0.592 \\
(\mathrm{NS})\end{array}$ \\
\hline $\begin{array}{l}\text { Laterality } \\
\text { Right breast } \\
\text { Left breast }\end{array}$ & $\begin{array}{l}24 \\
34\end{array}$ & $\begin{array}{l}12(50 \%) \\
14(41 \%)\end{array}$ & $\begin{array}{l}12(50 \%) \\
20(59 \%)\end{array}$ & $\begin{array}{l}\mathbf{0 . 5 0 6} \\
(\mathrm{NS})\end{array}$ \\
\hline $\begin{array}{l}\text { Histologic subtype } \\
\text { IDC-NST } \\
\text { Other subtypes }\end{array}$ & $\begin{array}{l}44 \\
14\end{array}$ & $\begin{array}{l}18(41 \%) \\
8(57 \%)\end{array}$ & $\begin{array}{c}26(59 \%) \\
6(43 \%)\end{array}$ & $\begin{array}{c}\mathbf{0 . 0 7 3} \\
(\mathrm{NS})\end{array}$ \\
\hline $\begin{array}{l}\text { Tumor grade } \\
\text { I } \\
\text { II }\end{array}$ & $\begin{array}{c}7 \\
29\end{array}$ & $\begin{array}{c}6(86 \%) \\
15(52 \%) \\
\end{array}$ & $\begin{array}{c}1(14 \%) \\
14(48 \%) \\
\end{array}$ & $0.008^{* * *}$ \\
\hline $\begin{array}{l}\text { Tumor size } \\
\text { T1 } \\
\text { T2 } \\
\text { T3 } \\
\end{array}$ & $\begin{array}{c}6 \\
28 \\
24\end{array}$ & $\begin{array}{c}5(83 \%) \\
11(39 \%) \\
10(42 \%)\end{array}$ & $\begin{array}{c}1(17 \%) \\
17(61 \%) \\
14(58 \%)\end{array}$ & $\begin{array}{c}\mathbf{0 . 1 3 3} \\
\text { (NS) }\end{array}$ \\
\hline $\begin{array}{l}\text { LN status } \\
\text { N0 } \\
\text { N1 } \\
\text { N2 } \\
\text { N2 }\end{array}$ & $\begin{array}{c}17 \\
15 \\
15 \\
11 \\
\end{array}$ & $\begin{array}{c}13(76 \%) \\
6(40 \%) \\
5(33 \%) \\
2(18 \%)\end{array}$ & $\begin{array}{c}4(24 \%) \\
9(60 \%) \\
10(67 \%) \\
9(82 \%)\end{array}$ & $0.012^{*}$ \\
\hline $\begin{array}{l}\text { AJCC stage } \\
\text { I } \\
\text { II } \\
\text { III }\end{array}$ & $\begin{array}{c}6 \\
24 \\
28\end{array}$ & $\begin{array}{l}6(100 \%) \\
13(54 \%) \\
7(25 \%)\end{array}$ & $\begin{array}{c}0 \\
11(46 \%) \\
21(75 \%)\end{array}$ & 0.002 ** \\
\hline $\begin{array}{l}\text { NPI } \\
\text { Good } \\
\text { Moderate } \\
\text { Poor } \\
\end{array}$ & $\begin{array}{l}13 \\
24 \\
21 \\
\end{array}$ & $\begin{array}{l}11(85 \%) \\
12(50 \%) \\
3(14 \%) \\
\end{array}$ & $\begin{array}{l}2(15 \%) \\
12(50 \%) \\
18(86 \%)\end{array}$ & $<0.001$ * * \\
\hline $\begin{array}{l}\text { Lymphocytic } \\
\text { infiltration } \\
\text { Minimal } \\
\end{array}$ & $\begin{array}{l}26 \\
32 \\
\end{array}$ & $\begin{array}{l}16(62 \%) \\
10(31 \%) \\
\end{array}$ & $\begin{array}{l}10(38 \%) \\
22(69 \%) \\
\end{array}$ & $0.021^{*}$ \\
\hline $\begin{array}{l}\text { Tumor margin } \\
\text { Free } \\
\text { Infiltrated }\end{array}$ & $\begin{array}{l}36 \\
22\end{array}$ & $\begin{array}{r}19(53 \%) \\
7(32 \%)\end{array}$ & $\begin{array}{l}17(47 \%) \\
15(68 \%)\end{array}$ & $\begin{array}{l}\mathbf{0 . 1 1 9} \\
\text { (NS) }\end{array}$ \\
\hline $\begin{array}{l}\text { Muscle invasion } \\
\text { Present } \\
\text { Absent }\end{array}$ & $\begin{array}{l}23 \\
35 \\
\end{array}$ & $\begin{array}{c}7(30 \%) \\
19(54 \%) \\
\end{array}$ & $\begin{array}{l}16(70 \%) \\
16(46 \%) \\
\end{array}$ & $\begin{array}{c}\mathbf{0 . 0 7 4} \\
(\mathrm{NS})\end{array}$ \\
\hline $\begin{array}{l}\text { Skin invasion } \\
\text { Present } \\
\text { Absent }\end{array}$ & $\begin{array}{l}28 \\
30 \\
\end{array}$ & $\begin{array}{l}11(39 \%) \\
15(50 \%)\end{array}$ & $\begin{array}{l}17(61 \%) \\
15(50 \%)\end{array}$ & $\begin{array}{c}0.412 \\
(\mathrm{NS})\end{array}$ \\
\hline $\begin{array}{l}\text { LVI } \\
\text { Present } \\
\text { Absent }\end{array}$ & $\begin{array}{l}17 \\
41\end{array}$ & $\begin{array}{c}3(18 \%) \\
23(56 \%)\end{array}$ & $\begin{array}{l}14(82 \%) \\
18(44 \%)\end{array}$ & $0.007^{* * *}$ \\
\hline
\end{tabular}

Table (1): Statistical Correlations between VCAM-1 Expression and Clinicopathological Parameters in IDC cases

$\mathrm{P}$ value was calculated by Chi-square test, $*=$ significant, ${ }^{* *}=$ highly significant, and NS= non-signif icant 

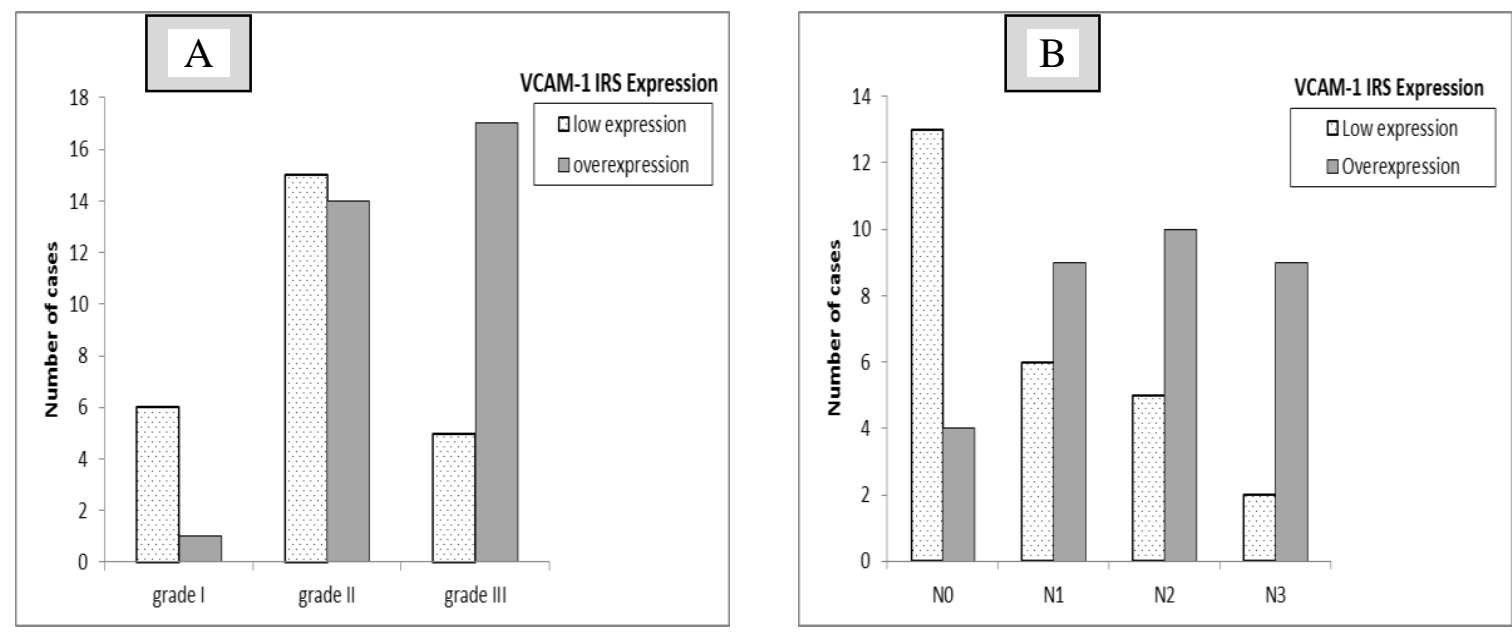

Graph 1: Correlation of VCAM-1 Expression with Tumor Grade (A) and Lymph Node Status (B).

\section{Discussion}

Breast carcinoma is a life threatening malignant tumor of females with an increa-sing incidence worldwide. Metastasis always impairs the curative effect of chemotherapeutic agents [7]. VCAM-1 expression has received increasing attention as a potential diagnostic and prognostic factor. The invasive capacity of breast cancer cells is determined by events in the microenvironment such as angiog-enesis and inflammation. VCAM-1 is suspected to be involved in inflamm-ationmediated cancer development, migration and tumor invasion; VCAM-1 activity is increased in cancer cells. It plays an important role in leukocytes recruitment to inflammation sites that is essential process for carcinogenesis in-cludeing enhanced cell proliferation, alterations in epigenetic events, and inappropriate gene expression, so increasing resistance to apoptosis. It also promotes neovascularization, inva-sion, and metastasis [8].

In the present study, VCAM-1 immunoreactivity was detected mainly in the cytoplasm of tumor cells. By contrast, there was very low or no detectable VCAM-1 expression in histologically normal mammary tissue adjacent to invasive tumor. These findings were consistent with the pattern observed in previous reports $[8,9]$. According the current study; significant positive correlation was found between VCAM-1 expression in breast carcinoma and tumor grade and histologic stage. These findings were consistent previous findings that demonstrated that the highest VCAM-1 expression levels were associated with moderately or poorly differentiated tumors and advanced stages of breast carcinoma $[2,10]$.

According to our findings; increased VCAM-1 expression was significantly associated with high incidence of LVI, high rates of LNM suggesting that VCAM-1 is a potential independent prognostic factor for breast carcinoma. Previous reports indicated that the overexpression of VCAM-1 was associated with tumor invasiveness and poor prognosis in breast cancer [11]. However, several studies concluded that it is not the up-regulation of VCAM-1 but the aberrant expression of this molecule was associated with progression of breast carcinoma [12]. The current 
study did not find any significant correlation between VCAM-1 expression and patients' age, necrosis, presence of in situ component, and invasion of skin and muscles. There was no significant difference in VCAM-1 expression in relation to histological type.

Conclusion: VCAM-1 expression is significantly correlated with prognosis of breast carcinoma, where higher expression levels tend to be associated with worse prognosis referring to tumor progression, and occurrence of metastasis. This suggests that VCAM- 1 is a potential independent prognostic factor for breast carcinoma and could be a suitable target for anti-cancer therapy.

\section{References}

1. Chen $Q$ and Massague $J$ (2012): Molecular pathways: VCAM-1 as a potential therapeutic target in metastasis. Clinical Cancer Research; 18(20): 5520-5525.

2. Sharma R, Khaket T, Dutta $\mathbf{C}$, Chakraborty $B$ and Mukherjee $T$ (2017): Breast cancer metastasis: Putative therapeutic role of vascular cell adhesion molecule-1. Cellular Oncology; 40: 199-208.

3. Karabulut S, Tas F, Tastekin D, Karabulut M, Yasasever CT, Ciftci R, et al (2014): The diagnostic, predictive, and prognostic role of serum epithelial cell adhesion molecule (EpCAM) and vascular cell adhesion molecule-1 (VCAM-1) levels in breast cancer. Tumor Biology; 35: 8849-8860.

4. Ellis I, Collins L, Ichihara $\mathbf{S}$ and MacGrogan G (2012): Invasive carcinoma of no special type. In Lakhani S, Ellis I, Schnitt S, Tan P and van de Vijver $M$ (editors): WHO Classification of Tumors of the Breast. $4^{\text {th }}$ edition. Lyon: International Agency for Research on Cancer; 34-38.

5. Amin M, Edge S, Greene F, Compton C, Gershenwald J, Brookland R, Meyer L, Gress D, Byrd D and Winchester D (2017): The Eighth Edition AJCC Cancer Staging Manual:
Continuing to build a bridge from a population-based to a more "personalized" approach to cancer staging. Cancer Journal for Clinicians; 67(2):93-99.

6. Maimaiti Y, Wang C, Mushajiang M, Tan J, Huang B, Zhou J, et al (2016): Overexpression of VCAM-1 is correlated with poor survival of patients with breast cancer. International Journal of Clinical and Experimental Pathology; 9(7):7451-7457.

7. Ferlay J, Colombet M, Soerjomataram I, Mathers C, Parkin D, Pineros M et al (2019): Estimating the global cancer incidence and mortality in 2018: GLOBOCAN sources and methods. International Journal of Cancer; 144(8): 1941-1953.

8. Wang $\mathbf{P}$, Weng $\mathbf{C}$, Hou $\mathbf{Y}$, Jian $\mathbf{S}$, Fang K, Hou M, et al (2014): Activation of VCAM-1 and its associated molecule CD44 leads to increased malignant potential of breast cancer cells. International Journal of Molecular Science; 15: 3560-3579.

9. Kulahci O, Esen H, Asut $E$ and Gungor S (2017): Association of ICAM-1, VCAM-1, CYCLIN D1 and Cathepsin D with Clinicopathological Parameters in Breast Carcinoma. Journal of Breast Health; 13: 5-9.

10. Zhang S, Zhang D, Gong M, Liao $C$ and Zou L (2017): High lymphatic vessel density and presence of lymphovascular invasion both predict poor prognosis in breast cancer. BioMed Center Journal of Cancer; 17:335.

11. Dieterich L and Detmar M (2016): Tumor lymphangiogenesis and new drug development. Advanced Drug Delivery Reviews; 99:148-160.

12. Schlesinger $M$ and Bendas $G$ (2015): Vascular cell adhesion molecule-1 (VCAM-1): An increasing insight into its role in tumorigenicity and metastasis. International Journal of Cancer; 136: 2504-2514. 